\title{
UNIVERSITYOF
}

FORWARD

THINKING

WESTMINSTER用

WestminsterResearch

http://www.westminster.ac.uk/westminsterresearch

\section{Contribution of street food to dietary intake of habitual urban consumers: a cross-sectional study in Kampala city, Uganda Sseguya, W., Matovu, N., Swann, J. and Draper, A.}

This is a copy of the accepted author manuscript of the following article: Sseguya, W., Matovu, N., Swann, J. and Draper, A. (2020) Contribution of street food to dietary intake of habitual urban consumers: a cross-sectional study in Kampala city, Uganda. Nutrition and Health. Advanced online publication. doi:10.1177/0260106020919629 . The final definitive version is available from the publisher Sage at:

https://dx.doi.org/10.1177/0260106020919629

(C) The Author(s) 2020

The WestminsterResearch online digital archive at the University of Westminster aims to make the research output of the University available to a wider audience. Copyright and Moral Rights remain with the authors and/or copyright owners.

Whilst further distribution of specific materials from within this archive is forbidden, you may freely distribute the URL of WestminsterResearch: ((http://westminsterresearch.wmin.ac.uk/)).

In case of abuse or copyright appearing without permission e-mail repository@westminster.ac.uk 


\section{Nutrition and Health}

\section{Contribution of street food to dietary intake of habitual urban consumers: A cross-sectional study in Kampala city, Uganda}

\begin{tabular}{|c|c|}
\hline Journal: & Nutrition and Health \\
\hline Manuscript ID & NAH-19-0163.R1 \\
\hline Manuscript Type: & Original Article \\
\hline $\begin{array}{r}\text { Date Submitted by the } \\
\text { Author: }\end{array}$ & 04-Mar-2020 \\
\hline Complete List of Authors: & $\begin{array}{l}\text { Sseguya, Wenceslaus; St. Francis Hospital Nsambya, } \\
\text { Matovu, Nicholas; Republic of Uganda Ministry of Health } \\
\text { Swann, Jessica; University of Westminster } \\
\text { Draper, Alizon; University of Westminster }\end{array}$ \\
\hline Keywords: & Street food, Diet, Meal, Nutrient, Urban, Uganda \\
\hline Abstract: & $\begin{array}{l}\text { Background: Street food has continued to be a more popular food source } \\
\text { in urban settings of developing countries and proving a vital urban } \\
\text { dietary source. However, its dietary contribution among patronising } \\
\text { urban populations is yet to be comprehensively understood. } \\
\text { Aim: To assess how street food contributes to dietary intake of habitual } \\
\text { street food consumers. } \\
\text { Methods: We conducted a community-based cross-sectional study } \\
\text { among habitual street food consumers in Kampala city. We defined } \\
\text { habitual intake as consumption of a serving of any street food for } \\
\geq 2 \text { days/week regardless of the food group and number of times } \\
\text { consumed in a particular day. Questionnaires were used to capture } \\
\text { quantitative data on sociodemographic characteristics, anthropometry, } \\
24-\text { hour diet intake and } 2 \text {-month street food consumption frequency. The } \\
\text { Nutritics } @ \text { diet analysis software version } 4.3 \text { and STATA version } 13.0 \\
\text { were used for nutrient and statistical analyses respectively. } \\
\text { Results: Street food contributed considerably to daily intake of fat } \\
\text { (49.1\%), sodium (38.4\%) and calcium ( } 36.5 \% \text { ) and least towards daily } \\
\text { intake of vitamin A (11.3\%). Majority of consumers opted for street food } \\
\text { at breakfast (50\%) whereas lunch and snacks featured the least for } \\
\text { overall street food inclusions (all } 20 \% \text { ). Overall, men demonstrated more } \\
\text { dietary intake and inclusion at meals from street food than women. } \\
\text { Conclusion: This study indicates significant contribution of street foods } \\
\text { for urban consumers but with men derive more benefit than women in } \\
\text { terms of nutrient intake and inclusion in meals from street food. }\end{array}$ \\
\hline
\end{tabular}

\section{SCHOLARONE ${ }^{\text {M }}$ Manuscripts}


Contribution of street food to dietary intake of habitual urban consumers: A cross-sectional study in Kampala city, Uganda.

Wenceslaus Sseguya ${ }^{1,2}$, Nicholas Matovu ${ }^{3}$, Jessica Swann², Alizon Draper ${ }^{2}$

${ }^{1}$ St Francis Hospital Nsambya, Kampala, Uganda

2 University of Westminster, London, United Kingdom

${ }^{3}$ Ministry of Health, Kampala, Uganda

\section{Corresponding Author:}

Wenceslaus Sseguya

P.O. Box 7146, Kampala

Email: seguyawenceslaus@yahoo.com 


\section{Contribution of street food to dietary intake of habitual urban consumers: 2 A cross-sectional study in Kampala city, Uganda.}

\section{Abstract}

4 Background: Street food has continued to be a more popular food source in urban settings of 5 developing countries and proving a vital urban dietary source. However, its dietary 6 contribution among patronising urban populations is yet to be comprehensively understood.

7 Aim: To assess how street food contributes to dietary intake of habitual street food 8 consumers.

9 Methods: We conducted a community-based cross-sectional study among habitual street 10 food consumers in Kampala city. We defined habitual intake as consumption of a serving of 11 any street food for $\geq 2$ days/week regardless of the food group and number of times consumed 12 in a particular day. Questionnaires were used to capture quantitative data on sociodemographic characteristics, anthropometry, 24-hour diet intake and 2-month street 14 food consumption frequency. The Nutritics ${ }^{\circledR}$ diet analysis software version 4.3 and STATA version 13.0 were used for nutrient and statistical analyses respectively.

Results: Street food contributed considerably to daily intake of fat (49.1\%), sodium $(38.4 \%)$

17 and calcium (36.5\%) and least towards daily intake of vitamin A (11.3\%). Majority of consumers opted for street food at breakfast (50\%) whereas lunch and snacks featured the least for overall street food inclusions (all 20\%). Overall, men demonstrated more dietary intake and inclusion at meals from street food than women.

Conclusion: This study indicates significant contribution of street foods for urban consumers but men derive more benefit than women in terms of nutrient intake and inclusion in meals of street foods.

Keywords: street food, diet, meal, urban, Uganda 


\section{$1 \quad$ Introduction}

2 Street food vending has been a feature of urban contexts. It is estimated that 2.5 billion

3 people globally consume them (Cardoso et al., 2014). Street food has gone beyond being

4 considered a signal of deprivation and a phenomenon for developing countries. It has become

5 a key form of nourishment and economic prosperity by offering affordable food and a means

6 of income-generation, especially in low-income countries (Draper, 1996; Tinker, 1997;

7 Cardoso et al., 2014). Given the current rate of urbanisation that is being experienced world

8 over (UNDESA, 2014), street food may continue being an embraced part of the food system.

9 Street food entails ready-to-eat foods and beverages sold and sometimes prepared in public

10 places, such as along urban streets, roadsides, and busy squares (FAO, 1989). In Uganda just

11 like many low-income countries, street food vending has become a very common practice in

12 urban areas, with street-vended foods comprising different kinds of meat, cereals, legumes,

13 fruits, vegetables, roots, tubers and beverages that are prepared and delivered in various

14 forms (Draper, 1996; Tinker, 1997; Namugumya and Muyanja, 2011; Hiamey et al., 2013).

15 The nutritional quality of street-vended foods also varies considerably from one street food

16 group to another and this further generally influences their respective purchase prices

17 (Mwangi et al., 2002). For the majority of urban Ugandans, these foods form an integral part

18 of their diets. Street food is considered relatively inexpensive and a more convenient food

option that counters the relatively high costs of living and busy work environments associated

with urban settings (Steyn et al., 2011). The patronisation of street food has not only been for

reasons of economic affordability and convenience, its appealing taste too has turned out to be an important attracting aspect (Draper, 1996; Steyn et al., 2011). The other is the nutrition value, whose role in addressing urban nutrition security challenges has been well documented (FAO, 1991; Draper, 1996; Tinker, 1997; Steyn et al., 2013). However, nutrition value is still not considered an important aspect for majority of consumers while making street food choices (Hiamey et al., 2013). 
1 The energy and macro-nutrient contribution of street food among consumers has been well

2 reported in various studies, but with variation by location. For instance, from previous

3 research, we find that geographic variations in energy contribution of street food have been

4 identified, ranging from $13-36 \%$ in East Africa (Namugumya and Muyanja, 2011; Van't

5 Riet et al., 2002) and from 46-48.3\% in West Africa (Oguntona et al., 1998; Becquey and

6 Martin-Prevel, 2010). Street foods contributed more energy towards men's diets than

7 women's in studies where such variations were assessed (Van `t Riet et al., 2001). Majority

8 of studies have highlighted that street food contribution towards carbohydrate seems highest,

9 ranging from 54-93.4\% (Namugumya and Muyanja, 2011; Oguntona et al., 1998; Becquey

10 and Martin-Prevel, 2010); and between 21.9-52\% towards fat. There is still dearth of data in

11 Uganda and Africa regarding the micronutrient contribution of street food especially among

12 habitual consumers, which leaves unknown potential risk for nutrient deficiencies or excesses

13 that may be associated with existing trends of street food choices. Notably, habituality in

14 street food consumption may also hinder consumption of foods from diverse sources, limiting

15 intake of certain nutrients in this particular population segment. Additionally, most of the

16 studies reporting dietary contribution of street food within the region were done more than

17 half a decade ago, yet there has been continuing drastic innovations in street food preparation

18 and trends influencing consumption over the years especially among urbanites. In this study

19 therefore, we set out to analyse the overall diet composition, and nutrient contribution of

20 street food for habitual street food consumers in Kampala city. We also sought to understand

21 gender-related differences in street food consumption and contribution to dietary intake.

\section{Methods}

\section{Study setting:}

24 The study was conducted in Kampala, the biggest city and capital of Uganda, with a 25 population of more than 1.5 million people (Uganda Bureau of Statistics, 2014). Data were 
1 collected in May and June 2017 from the five administrative city divisions namely, Kampala

2 central, Kawempe, Lubaga, Makindye and Nakawa. Major economic activities in Kampala

3 are employment income and small- and large-scale trading, all of which account for more

4 than $80 \%$ of the working population (Uganda Bureau of Statistics, 2002).

\section{$5 \quad$ Study design and population:}

6 This was a descriptive cross-sectional study that employed quantitative methods of data

7 collection and analysis. The study population were street food consumers aged 18 years and

8 above, residing and or working in the five administrative divisions of Kampala capital city in

9 May and June 2017. Habitual consumption was defined as consumption of a serving of any

10 street food, for two (2) or more days a week regardless of the food group and the number of

11 times consumed in a particular day.

\section{Eligibility}

13 Habitual street food consumers aged 18 years and over who had been residing and /or

14 working within the five city divisions for at least two months prior to the study were 15 included. All individuals who met the inclusion criteria but declined signing the informed 16 consent, were operating at more than one station during daytime, were street food vendors, 17 were having physical, auditory or speech disability were excluded.

\section{Sample size and sampling procedure:}

19 The sample size was calculated using Kish's formula for cross sectional studies (Kish, 1965).

20 Assuming a standard normal value corresponding to the $95 \%$ confidence interval, a margin of error of 5\%, and an estimated proportion of habitual food consumers of $12.0 \%$ (in a rather similar setting of Free town, South Africa) (Steyn et al., 2011) yielded a calculated sample size of 163 respondents. 
1 We purposively identified two major trading centres in each division of Kampala, totalling up 2 to 10 major trading centres. Individuals residing or working within half-mile radius of each

3 selected trading centre meeting the inclusion criteria formed the sampling frame, from which

4 the final sample was randomly selected. Parking stations were used to select riders and taxi

5 operators, residential houses to select individuals at home, business buildings to select

6 traders, and working spaces to select manual labourers. Only individuals who self-reported

7 eating street food at least two days in a typical week on first contact were listed on the

8 sampling frame. The interviews were conducted from space of homes and work places

9 deemed comfortable by participants. All divisions in Kampala contributed an almost equal 10 number of respondents (approximately 32 respondents from each division).

\section{Data collection:}

12 Interviewer-led pretested semi-structured questionnaires were used to collect information 13 from respondents. Two nutritionists, previously trained on the study and data collection tools, 14 led the interviews in supervision of the first author. The questionnaires had been translated 15 into the commonly used language 'Luganda' prior to data collection to ensure that similar 16 questions were asked without alteration in meaning, which consequently reduced on 17 interviewer bias. The questionnaires collected information on sociodemographic 18 characteristics, dietary intake, food consumption frequency, and anthropometric data.

\section{Study Variables and their measurements:}

20 Sociodemographic characteristics of participants that were captured by the interviewer-led 21 questionnaire included; age, marital status, religion, education, socioeconomic status, 22 monthly income.

23 Weight and height were recorded from which body mass index (BMI) was computed. These were measured using a Seca ${ }^{\circledR}$ scale and a standardised height meter tape respectively with 
1 participants in light clothing and shoes off while following steps in the anthropometric

2 procedure manual (CDC National Center for Health Statistics, 2007). The measurements

3 were respectively repeated for each participant and the average taken. The weight was

4 recorded to the nearest $0.1 \mathrm{~kg}$ while the height was recorded to the nearest $0.1 \mathrm{~cm}$. BMI was

5 then computed for each participant in $\mathrm{kg} / \mathrm{m}^{2}$.

6 Dietary intake was assessed using a single 24-hour diet intake recall questionnaire, which

7 captured data on foods and beverages consumed by the participants in the previous day

8 (between midnight and midnight). To allow for maximum recall and improved accuracy of

9 intake estimates among participants, the 5-step multiple-pass approach (Robertson et al., 10 2005) and a copy of 'food album' (supplementary material) were incorporated into the 11 interview procedure. This study specifically focused on assessing dietary intake of the 12 following nutrients: protein, carbohydrates, total fat, saturated fat, fibre, calcium, sodium, 13 vitamin $\mathrm{A}$, folate, vitamin $\mathrm{C}$, and iron.

14 A 2-month semi-quantitative food frequency questionnaire (FFQ) was used to assess the frequency and portions of street food consumption, which information was also used to validate analyses from the 24-hour recall thus reflecting usual intake. Participants were required to recall within the previous two months, the number of times each food listed in the FFQ was usually consumed, indicating the approximate portions (thereafter converted to grams) eaten at each specified time.

Statistical analysis

21 Dietary intake data from the 24-hour recall questionnaire of each participant was entered into 22 the Nutritics ${ }^{\circledR}$ software version 4.3 (Dublin, Ireland) to obtain individual energy and nutrient 23 values. The analysis was made for total energy, protein, fat, carbohydrate, fibre, calcium, 24 sodium, vitamin $\mathrm{A}$, vitamin $\mathrm{C}$, folate, and iron. These were selected owing to their public 25 health importance regarding major deficiency concerns and epidemiological links to chronic 
1 diseases in adult populations (IFPRI, 2014). Food composition tables for Uganda HarvestPlus 2 (Hotz et al., 2012), and Tanzania (Lukmanji et al., 2008) were used to add the missing food 3 items and recipes to the Nutritics software. Analyses for the different nutrients were 4 expressed as percentage energy $(\% \mathrm{E})$ and grams $(\mathrm{g})$ for the macronutrients as appropriate, 5 and as milligrams $(\mathrm{mg})$ and micrograms $(\mu \mathrm{g})$ for the micronutrients. Nutrient values for all 6 participants were later transferred to STATA version 13.0 (Collage Station, TX, USA) and 7 merged with the existing variables from the sociodemographic and anthropometric 8 characteristics.

9 To obtain proportions of individuals that included street foods at different meal occasions, we 10 employed a scoring approach using $\mathrm{MS}^{\circledR}$ Excel (version 2016). An individual was to be assigned a score of either 1 or 0 for each meal occasion (breakfast, lunch, supper and snack) depending on whether he/she included any street food or not, that is, for every meal occasion where a street food was reported to be consumed, a score of 1 was assigned, and a score of 0/zero where street food was not consumed. For instance, if an individual included any kind of street food for breakfast, he/she would earn a score of 1 for breakfast, and if street food was not included, he/she would earn a score of zero for breakfast. The same would apply for 17 Lunch, supper and snack. Every meal occasion was scored independently for each participant. Participants who missed a meal occasion were excluded from this analysis as scoring could only be done for a fulfilled meal occasion. Gender-based proportions were derived based on the total number male and female participants as a denominator.

21 Sociodemographic characteristics were presented as means and standard deviation for continuous variables, and as percentages for categorical variables. All outputs from the analyses were further stratified by gender. 


\section{$1 \quad$ Results}

2 Data from 160 habitual street food consumers (40\% men and 60\% women) were analysed, 3 leaving the three (03) who had incomplete data on key variables. The characteristics of the

4 study population disaggregated by gender are summarised in Table 1 . The mean age of the 5 participants was 29.6 years (SD: 11.5 years) with no significant difference between men and 6 women. Women had a significantly higher mean BMI compared to men (26.1 vs. 23.2; $7 \mathrm{p}<0.001)$. Gender was also associated with marital status $(\mathrm{p}=0.028)$, employment $(\mathrm{p}<0.001)$, 8 individual income $(p=0.004)$, and street food consumption frequency $(p=0.044)$, whereas 9 majority of men were single, manual labourers, earned more and had a higher street food 10 consumption compared to women.

\section{Street food contribution towards the daily nutrient intake of habitual consumers}

12 The nutrient contribution of street foods towards total daily intakes is presented in Table 2.

13 Overall, for macronutrients, highest contribution was to fat intakes $(49.1 \%)$ and lowest to 14 carbohydrate intakes $(25.6 \%)$. Only $30 \%$ of overall daily energy intake came from street food. For daily micronutrient intakes, the highest contribution was to sodium $(38.4 \%)$ and calcium (36.5\%), contributing more than a third of daily intake. Vitamin A $(11.3 \%)$ and vitamin $\mathrm{C}(24.1 \%)$ on the other hand recorded less than a quarter of daily intake contribution. The amount of all nutrients obtained from street foods was significantly higher in men than women, and so were percent nutrient contributions from street food across all nutrients. Street food contribution across all nutrients ranged from $27.9 \%-52.1 \%$ in men and $4.6 \%-38.4 \%$ in women. In men, the contribution of street food towards the diet was highest for fat $(52.1 \%)$, sodium (50.8\%) and calcium (50.6\%), whereby slightly over a half of the total dietary intake of these nutrients was derived from street food. On the other hand, in women, street food contribution towards the diet was similarly highest for fat $(38.4 \%)$, sodium $(27.7 \%)$ and calcium $(23.2 \%)$. 


\section{Proportion of participants including street foods at various meal occasions}

2 Regarding how street food featured in the different meal occasions as shown in Figure 1,

3 majority of participants opted to include street food at breakfast (50\%), whereas lunch and

4 snacks featured the least overall street food inclusions from participants (all 20\%). Men had a

5 higher proportion of street food inclusion than women for all meal occasions.

\section{Discussion}

\section{Contribution to daily energy and micronutrient intake from street food}

8 This study set out to assess the contribution of street food to the diets of habitual street food

9 consumers. Street food contributes a substantial amount of energy (30.1\%) towards the daily 10 intake of habitual consumers. Compared with $22.4 \%-25.6 \%$ energy intake reported among 11 street food vendors in central and eastern urban regions of Uganda (Namugumya and 12 Muyanja, 2011), these findings may imply that urban habitual street food consumers have higher intakes of energy from street foods than street food vendors. Noteworthy in this population segment is the significant variation between men and women regarding street food energy contribution, with men recording about twice as much as women $(41.6 \%$ vs $19.9 \%$ respectively). Similar findings were reported by Van`t Riet, et al (2002) in Kenya, and Oguntona, et al (1998) in Nigeria, who also found higher energy intake in men than women, although figurative differences were reported (26-35.4\% vs $16.7-22.1 \%$ in Kenya and 50.3\% vs $48.3 \%$ in Nigeria). The energy intake figure observed in this study may be attributed to the high fat intake from street food that tends to be influenced by high demand for appealing deep-fried foods (Steyn et al., 2011). The recorded near half (49.1\%) of the total fat intake from street food in this study shows fat to have been the main energy contributor compared to protein $(29.7 \%)$ and carbohydrate $(25.6 \%)$. The higher fat intake from street food recorded in men than women may also be attributed to the high consumption frequency of street foods observed among men than women in the current study. Similar results where street food 
1 contributed more to fat than any other macronutrient have been reported in Kenya (Van't Riet

2 et al., 2002) and Burkina Faso (Becquey and Martin-Prevel, 2010) but not in Nigeria

3 (Oguntona et al., 1998). These studies still reported higher intakes among men than women.

$4 \quad$ The fact that in the present study only habitual consumers and all participants from various

5 circles of employment were considered unlike the studies in Kenya, Burkina Faso and

6 Nigeria, could explain the observed figurative variations. But still, it is worthy to note that

7 energy and macronutrient intake among street food consumers in Uganda is similar to other

8 African countries. High energy intake is a risk for overweight and obesity (World Health

9 Organization, 2014). Whereas the energy contribution from street foods with this status quo

10 may appear safe, caution needs to be exercised regarding the choices of the energy sources

11 especially fat, which has been shown to be a dietary risk factor for non-communicable

12 diseases (World Health Organization, 2014). In this regard, men ought to exercise more

13 caution on energy intake from street food, because a substantial contribution was recorded

14 from street foods.

\section{Contribution to daily micronutrient intake from street food}

16 The six micronutrients we focused on were, calcium, sodium, iron, vitamin $\mathrm{A}$, vitamin $\mathrm{C}$ and

17 folate. Street food proved a considerable source of dietary sodium and calcium but low

18 vitamin A. More than a third of dietary sodium and calcium for this population segment of 19 consumers comes from street food. There is dearth of information on micronutrient 20 contribution of street food in Africa, thus providing just a few studies to compare, most of 21 which are based on reference intake values. Studies on sodium and folate intake among street 22 food consumers in Africa are still scanty and barely conducted among adults. However, 23 studies that have assessed calcium, vitamin $\mathrm{A}$, vitamin $\mathrm{C}$ and iron have reported varying 24 figures. For example, Oguntona et al (1998) reported 46.2\% for calcium, 35.2\% for iron, $2555.3 \%$ for vitamin A, 57.3\% for vitamin C among adults in Nigeria, all of which are higher 
1 than those reported in the current study. Moreover, higher intake of these micronutrients in

2 the latter were recorded in women than men (Oguntona et al., 1998). Contrariwise, in

3 neighbouring Kenya (Van't Riet et al., 2002), among iron, calcium and vitamin A that were

4 assessed, all but vitamin A were reportedly lower than observed in this study. Moreover, a

5 similar finding of men having a higher micronutrient intake from street food than women was

6 reported by the same study as was observed in this current study. This variation may indicate

7 that street food consumers within east Africa may differ from their West African counterparts

8 in regard to their street food choices. This could be due to differing cultural and geographical

9 influence on kind of street foods available and population choices that may be associated with

10 the two regions. Women in this street food consuming population also have very low intake

11 of vitamin and mineral sources from street food. This may be due to having limited access

12 and affordability of these foods because of their cultural confinement in homes and the

13 relatively high cost associated with such foods (Sasson, 2012; Mwangi et al., 2002).

14 Therefore, micronutrient deficiencies may likely occur among habitual street food consumers

15 especially women if additional dietary sources do not provide adequate micronutrients to

16 compensate for the low intake from street food

\section{Street food inclusion in daily meals}

18 Street foods among this habitual consuming population are popularly included at breakfast 19 compared to other meals. Similar findings have been reported by Nago et al (2010) who 20 found high consumption of street food at breakfast among school-going children in Benin 21 (Nago et al., 2010). This may be attributed to the limited time available to prepare or settle 22 for home-made breakfast meals vis-a-vis typical morning work rush associated with urban 23 dwellers that drives them to opt for more convenient ready-made street foods (Johnson and 24 Yawson, 2000). Most foods consumed as or accompanying a breakfast beverage can take 25 considerable time and cost to prepare especially for a small portion, which will normally go 
1 above the cost off the street or the time it takes to have it on the street (Osei Mensah et al.,

2 2013). Foods observed to be commonly included in breakfast were chapatti, mandazi,

3 Ugandan pancakes, deep fried cassava, rolex (chapatti roll), katogo (mixed combination of

4 matooke and sauce). The big proportion of unmarried men in our study may explain the

5 observed high inclusion of street foods in most meals among men than women. Food

6 preparation is a role that is attached to women in the cultural confines of Uganda, and

7 therefore men who are not married will opt for out of home sources of food/meals. Majority

8 of foods observed from reported intake for breakfast are oil-rich (deep fried casaava, sweet

9 potatoes, chapattis, mandazi, samosas,), and this may explain the high contribution of fat

10 from street foods. Men who in this population are seen to have a relatively higher street food

11 intake at breakfast than women stand risk for excess fat intake should the observed trend of

12 street food patronisation carry on. Moreover, the likelihood of underreporting of fat intake

13 among participants that is commonly reported (Macdiarmid and Blundell, 1998) may mean

14 the value indicated in our study is likely lower than the actual value. This could imply that

15 more fat may likely have been consumed than reported pointing to a bigger threat than our

16 study may have indicated.

\section{Strengths and limitations}

18 One of the key strengths of this study is that it incorporates gender-based analysis of street

19 food contributions to the daily diets of habitual consumers in regard to both macro and micro

20 nutrients, which has not been well studied in the region. Studies that incorporated gender-

21 based comparisons have mainly focused on macronutrient differences. Additionally, we

22 present results from a habitual street food consuming population given that our urban settings

23 are increasingly adopting street food as a major and accessible food source, which we believe

24 could impact nutritional status. However, our study is limited by the fact that it was based on

25 individual intake recall that may not reflect actual intake. Whereas we believe that analysis of 
1 saturated fat would add more strength to our study findings, this was limited by failure of

2 study participants to discern and report on kinds of fat/oil consumed as these were not be 3 provided for by vendors. The fact that there may be variation of street food types across the 4 different parts of the country and across different countries could limit generalisation of our 5 findings to a broader population. Furthermore, whereas food tables that we used had most of 6 the common foods and recipes used within Uganda, we cannot rule out food vendors that may 7 have employed recipes which may be slightly different from the documented. Nonetheless, 8 our findings highlight public health nutritional implications relating to an apparent urban 9 nutrition transition indicative of habituality in street food consumption.

10 Conclusion

11 Street food offers considerable nutrition benefits towards the diet of habitual consumers, 12 although these benefits are much more enjoyed among men than women. There is however 13 concern regarding low dietary supply of micronutrients from street food choices of this 14 habitual consuming urban population. Without inclusion of micronutrient-rich foods from 15 other diet sources, this population can stand a micronutrient deficiency risk should future 16 patronising of street food exceed what we observed in our study period. It is therefore 17 important that this population, particularly the physiologically at-risk women to constantly 18 include adequate amounts of food rich in iron, folate, calcium and vitamin $\mathrm{A}$ in their daily 19 homemade meals or any other sources to boost their intake. Otherwise the micronutrient 20 profile of street foods needs to be enhanced, which can be through promoting use of 21 micronutrient-fortified ingredients in street food preparation. Men on the other hand need caution on fat and salt intake, since a substantial portion comes from their street food choices.

\section{Acknowledgement}

24 The authors are thankful to the study participants for the valuable work-time they generously 25 set aside to participate in the study. 


\section{$1 \quad$ Funding}

2 The study received funding from the Commonwealth scholarship commission (CSC) as a

3 scholarly research project for W.S. The study also received travel funds from the Santander

4 academic travel grant for W.S. The funders had no role in design, analysis, or writing this

5 article.

\section{$6 \quad$ Availability of data and materials}

7 Datasets generated and analysed during the study are not publicly available due to terms of 8 participant consent but are available in anonymised form from the corresponding author on 9 reasonable request. Supplementary visual material used in diet assessment associated with 10 this article can be found at https://1drv.ms/p/s!AuEGGCk-VZsSs3zpnw5B5LpbA18d

\section{Conflict of interest}

12 None

\section{Authors' contributions}

14 W.S, J.S. and A.D. contributed in formulating the research question and designing the study.

15 W.S. and N.M. contributed in carrying out the study and analysing the data. W.S, J.S, A.D. 16 and N.M. contributed in writing and reviewing the final manuscript.

\section{Consent for publication}

18 Not applicable

19 Ethical approval

20 This study was conducted in accordance with guidelines laid down in the Declaration of 21 Helsinki and all procedures involving research study participants were approved by the 22 University of Westminster research ethics committee [ETH1617-1153], and in Uganda by St. 23 Francis Hospital Nsambya REC [UG-REC-020]. Written informed consent was obtained 24 from all participants. 


\section{$1 \quad$ References}

2 Becquey E and Martin-Prevel Y. (2010) Micronutrient adequacy of women's diet in urban 3 Burkina Faso is low. The Journal of Nutrition 140: 2079S-2085S.

4 Cardoso R, Companion M and Marras SR. (2014) Street Food: Culture, Economy, Health 5 and Governance, London \& New York: Routledge.

6 CDC National Center for Health Statistics. (2007) National Health and Nutrition 7

8 Draper A. (1996) Street Foods in Developing Countries: The Potential for Micronutrient 9 Fortification.

FAO. (1989) Street foods: A summary of FAO studies and other activities relating to street food, Rome: Food and Agricultural Organization.

FAO. (1991) Street foods in developing countries: lessons from Asia. . Rome: Food and 14 Hiamey SE, Amuquandoh FE and Boison GA. (2013) Are we indeed what we eat? Street 15 food consumption in the Market Circle area of Takoradi, Ghana. Nutrition and Health 22: $215-235$.

Hotz C, Lubowa A, Sison C, et al. (2012) A Food Composition Table for Central and Eastern Uganda.

IFPRI. (2014) Global Nutrition Report 2014: Actions and Accountability to Accelerate the World's Progress on Nutrition. Washington, DC.: International Food Policy Research Institute.

Johnson T and Yawson R. (2000) Report on workshop for stakeholders, policy makers and regulators of street-food vending in Accra, at Miklin Hotel,, 25 -26th September,. Accra: DFID/NRI/FRI.

Kish L. (1965) Survey Sampling, New York: John Wiley and Sons, Inc.

Lukmanji Z, Hertzmark E, Mlingi N, et al. (2008) Tanzania Food Composition Tables.

Macdiarmid J, and Blundell J. (1998) Assessing dietary intake: Who, what and why of under28 reporting. Nutrition Research Reviews 11(2), 231-253. 
1 Mwangi AM, Den Hartog AP, Mwadime RK, et al. (2002) Do Street Food Vendors Sell a

2

3

4 5

6

7 8

9

10

Sufficient Variety of Foods for a Healthful Diet? The Case of Nairobi. Food and Nutrition Bulletin 23: 48-56.

Nago SE, Lachat CK, Huybregts L, et al. (2010) Food, energy and macronutrient contribution of out-of-home foods in school-going adolescents in Cotonou, Benin. British Journal of Nutrition 103: 281-288.

Namugumya BS and Muyanja C. (2011) Contribution of street foods to the dietary needs of street food vendors in Kampala, Jinja and Masaka districts, Uganda. Public Health Nutrition 15: 503-1511.

Oguntona C, Razaq MA and Akintola T. (1998) Pattern of Dietary Intake and Consumption of Street Foods among Nigerian Students. Nutrition and Health 12: 247-256.

Osei Mensah J, Aidoo R and Appiah N. (2013) Analysis of street food consumption across various income groups in the Kumasi metroplis of Ghana. International Review of Management and Business Research 2: 951-961.

Robertson C, Conway R, Dennis B, et al. (2005) Attainment of precision in implementation of 24h dietary recalls: INTERMAP UK. British Journal of Nutrition 94: 588-594.

Sasson A. (2012) Food security for Africa: an urgent global challenge. Agriculture \& Food Security 1.

Steyn NP, Labadarios D and Nel JH. (2011) Factors which influence the consumption of street foods and fast foods in South Africa-a national survey. Nutrition Journal 10: 104-104.

Steyn NP, Mchiza Z, Hill J, et al. (2013) Nutritional contribution of street foods to the diet of people in developing countries: a systematic review. Public Health Nutrition 17: $1363-1374$.

Tinker I. (1997) Street Foods: Urban Food and Employment in Developing Countries, New York: Oxford University Press, Inc.

Uganda Bureau of Statistics. (2002) The 2002 Uganda Population and Housing Census Economic Characteristics. Kampala: Uganda Bureau of Statistics.

Uganda Bureau of Statistics. (2014) National Population and Housing Census 2014. Kampala: Uganda Bureau of Statistics (UBOS). 
1 UNDESA. (2014) World Urbanization Prospects: The 2014 Revision Highlights. New York:

2

3 Van 't Riet H, den Hartog AP, Mwangi AM, et al. (2001) The role of street foods in the 4 dietary pattern of two low-income groups in Nairobi. European Journal of Clinical Nutrition 55: 562-570.

Van't Riet H, den Hartog A and Mwangi A. (2002) Non-home prepared foods: contributing to energy and nutrient intake of consumers living in two low income areas in Nairobi. Public Health Nutrition 4: 515-522.

WHO. (2014) Global status report on noncommunicable diseases 2014. Geneva: World Health Organization.

World Health Organization. (2014) Global status report on noncommunicable diseases 2014. Geneva: World Health Organization. 
1 Table 1: Sociodemographic, Anthropometric, Street Food Consumption Characteristics of 2 Study Participants

\begin{tabular}{|c|c|c|c|c|}
\hline Parameter & Overall & Men & Women & P value \\
\hline No. (n\%) & $160(100 \%)$ & $64(40.0)$ & $96(60.0)$ & \\
\hline Age $($ mean $\pm \mathrm{SD})$ & $29.6 \pm 11.5$ & $28.9 \pm 9.9$ & $30.1 \pm 12.5$ & 0.785 \\
\hline $\mathrm{BMI}($ mean $\pm \mathrm{SD})$ & $24.9 \pm 4.8$ & $23.2 \pm 3.0$ & $26.1 \pm 5.3$ & $<0.001^{*}$ \\
\hline Marital Status, n (\%) & & & & $0.028 *$ \\
\hline Married & $68(42.50)$ & 40.63 & 43.75 & \\
\hline Single & $62(38.75)$ & 50.00 & 31.25 & \\
\hline Widowed & $10(6.25)$ & 1.56 & 9.38 & \\
\hline Divorced/separated & $20(12.50)$ & 7.81 & 15.63 & \\
\hline Education level, n (\%) & & & & 0.435 \\
\hline No formal education & $8(5.00)$ & 3.13 & 6.25 & \\
\hline Primary & $53(33.13)$ & 29.69 & 35.42 & \\
\hline Secondary & $87(54.38)$ & 56.25 & 53.13 & \\
\hline Tertiary & $12(7.50)$ & 10.94 & 5.21 & \\
\hline Socioeconomic status (SES), n (\%) & & & & 0.123 \\
\hline Highest category ( $2^{\text {nd }}$ quantile) & $48(30.00)$ & 35.94 & 26.04 & \\
\hline Lower category ( $1^{\text {st }}$ quantile $)$ & $112(70.00)$ & 64.06 & 73.96 & \\
\hline Employment category, n (\%) & & & & $<0.001 *$ \\
\hline Transport & $5(3.13)$ & 7.81 & 0.00 & \\
\hline Sales & $47(29.38)$ & 15.63 & 38.54 & \\
\hline Manual Labour & $51(31.87)$ & 53.13 & 17.71 & \\
\hline Unemployed & $49(30.63)$ & 17.19 & 39.58 & \\
\hline Office-based & $8(5.00)$ & 6.25 & 4.17 & \\
\hline Individual Monthly income, n (\%) & & & & $0.004^{*}$ \\
\hline Less than $\$ 60$ & $90(56.25)$ & 40.63 & 66.67 & \\
\hline Between $\$ 60-\$ 120$ & $39(24.38)$ & 32.81 & 18.75 & \\
\hline Between $\$ 120.1-\$ 180$ & $15(9.38)$ & 9.38 & 9.38 & \\
\hline More than $\$ 180$ & $16(10.00)$ & 17.19 & 5.21 & \\
\hline Frequency of street food, $n(\%)$ & & & & $0.044^{*}$ \\
\hline High ( 5 or more times a week) & $102(63.75)$ & 73.44 & 57.29 & \\
\hline Low (2-4 times a week) & $58(36.25)$ & 26.56 & 42.71 & \\
\hline
\end{tabular}
Low $(2-4$ times a $58(36.25)$ 42.71

3 BMI, body mass index; SD, standard deviation. Data are presented as (mean $\pm \mathrm{SD}$ ), and frequencies (\%) as 4 described. p-values are for comparison between men and women obtained by Mann Whitney $U$ test for 5 continuous variables and by Fisher exact test for categorical variables. * Significant association 
12 Table 2: Street food contribution towards the daily nutrient intake of habitual consumers

\begin{tabular}{|c|c|c|c|c|c|c|c|c|c|c|c|}
\hline \multirow[b]{2}{*}{ Nutrients } & \multicolumn{3}{|l|}{ Overall } & \multicolumn{2}{|c|}{ Men } & \multicolumn{4}{|c|}{ Women } & \multirow{2}{*}{ P value ${ }^{t}$} & \multirow{2}{*}{$\begin{array}{l}\mathbf{P} \\
\text { value }^{\gamma}\end{array}$} \\
\hline & $\begin{array}{l}\text { Total Intake } \\
(\text { mean } \pm \mathrm{SD})\end{array}$ & $\begin{array}{l}\text { Street food } \\
(\text { mean } \pm \mathrm{SD})\end{array}$ & $\begin{array}{l}\% \text { street } \\
\text { food }\end{array}$ & $\begin{array}{l}\text { Total intake } \\
(\text { mean } \pm \mathrm{SD})\end{array}$ & $\begin{array}{l}\text { Street food } \\
(\text { mean } \pm \mathrm{SD})\end{array}$ & $\begin{array}{l}\text { \% street } \\
\text { food }\end{array}$ & $\begin{array}{l}\text { Total intake } \\
(\text { mean } \pm \mathrm{SD})\end{array}$ & $\begin{array}{l}\text { Street food } \\
(\text { mean } \pm \mathrm{SD})\end{array}$ & $\begin{array}{l}\% \\
\text { street } \\
\text { food }\end{array}$ & & \\
\hline Energy / kcal & $2104 \pm 805.8$ & $632.3 \pm 738.9$ & 30.1 & $2457.3 \pm 834.4$ & $1022.9 \pm 910.1$ & 41.6 & $1868.5 \pm 696.3$ & $371.8 \pm 439.6$ & 19.9 & $<0.001^{*}$ & $<0.001^{*}$ \\
\hline Protein $(g)$ & $55.5 \pm 25.8$ & $16.5 \pm 21.3$ & 29.7 & $62.8 \pm 24.7$ & $26.0 \pm 24.9$ & 41.4 & $50.7 \pm 25.5$ & $10.2 \pm 15.7$ & 20.1 & $0.001 *$ & $<0.001^{*}$ \\
\hline Carb (g) & $370.4 \pm 145.5$ & $94.8 \pm 121.9$ & 25.6 & $431.1 \pm 151.2$ & $159.8 \pm 155.0$ & 37.1 & $329.9 \pm 127.0$ & $51.4 \pm 64.8$ & 15.6 & $<0.001^{*}$ & $<0.001^{*}$ \\
\hline Fat $(\mathrm{g})$ & $40.1 \pm 28.1$ & $19.7 \pm 23.5$ & 49.1 & $48.4 \pm 32.0$ & $25.2 \pm 14.3$ & 52.1 & $34.6 \pm 23.7$ & $13.3 \pm 17.6$ & 38.4 & $0.004 *$ & $<0.001^{*}$ \\
\hline Fibre (g) & $37.7 \pm 24.8$ & $10.9 \pm 18.5$ & 28.9 & $39.3 \pm 14.8$ & $18.9 \pm 26.10$ & 48.1 & $36.5 \pm 29.7$ & $5.7 \pm 7.3$ & 15.6 & $0.024 *$ & $<0.001^{*}$ \\
\hline Calcium (mg) & $351.0 \pm 296.3$ & $128.2 \pm 250.8$ & 36.5 & $426.2 \pm 374.4$ & $215.8 \pm 366.6$ & 50.6 & $300.9 \pm 218.3$ & $69.8 \pm 87.2$ & 23.2 & $0.001 *$ & $<0.001^{*}$ \\
\hline Sodium (mg) & $1425.9 \pm 782.5$ & $548.0 \pm 612.1$ & 38.4 & $1643.1 \pm 787.8$ & $835.1 \pm 692.5$ & 50.8 & $1281.0 \pm 748.5$ & $354.7 \pm 463.1$ & 27.7 & $0.005^{*}$ & $<0.001^{*}$ \\
\hline Iron (mg) & $14.1 \pm 6.5$ & $4.2 \pm 5.3$ & 29.7 & $15.8 \pm 6.4$ & $6.8 \pm 6.6$ & 43.0 & $13.0 \pm 6.4$ & $2.3 \pm 3.1$ & 17.7 & $0.005^{*}$ & $<0.001^{*}$ \\
\hline Vit.C (mg) & $103.8 \pm 89.0$ & $25.1 \pm 42.7$ & 24.1 & $101.3 \pm 85.9$ & $41.1 \pm 55.8$ & 40.6 & $105.4 \pm 91.4$ & $14.4 \pm 26.4$ & 13.7 & 0.740 & $<0.001^{*}$ \\
\hline Vit.A ( $\mu \mathrm{g})$ & $1011.4 \pm 3077.6$ & $113.9 \pm 261.1$ & 11.3 & $722.5 \pm 907.2$ & $201.3 \pm 371.0$ & 27.9 & $1203.8 \pm 3887.6$ & $55.7 \pm 119.35$ & 4.6 & 0.911 & $<0.001^{*}$ \\
\hline Folate $(\mu \mathrm{g})$ & $267.1 \pm 160.6$ & $67.0 \pm 89.4$ & 25.0 & $261.3 \pm 127.1$ & $106.0 \pm 108.3$ & 40.6 & $271.0 \pm 180.1$ & $41.0 \pm 62.5$ & 15.1 & 0.925 & $<0.001 *$ \\
\hline
\end{tabular}

${ }^{\mathbf{t}}$ Comparison of total intake of men and women, ${ }^{\boldsymbol{r}}$ Comparison of street food consumption of men and women. $*$ Denotes significant difference between men and women. P values obtained by Mann Whitney U test 


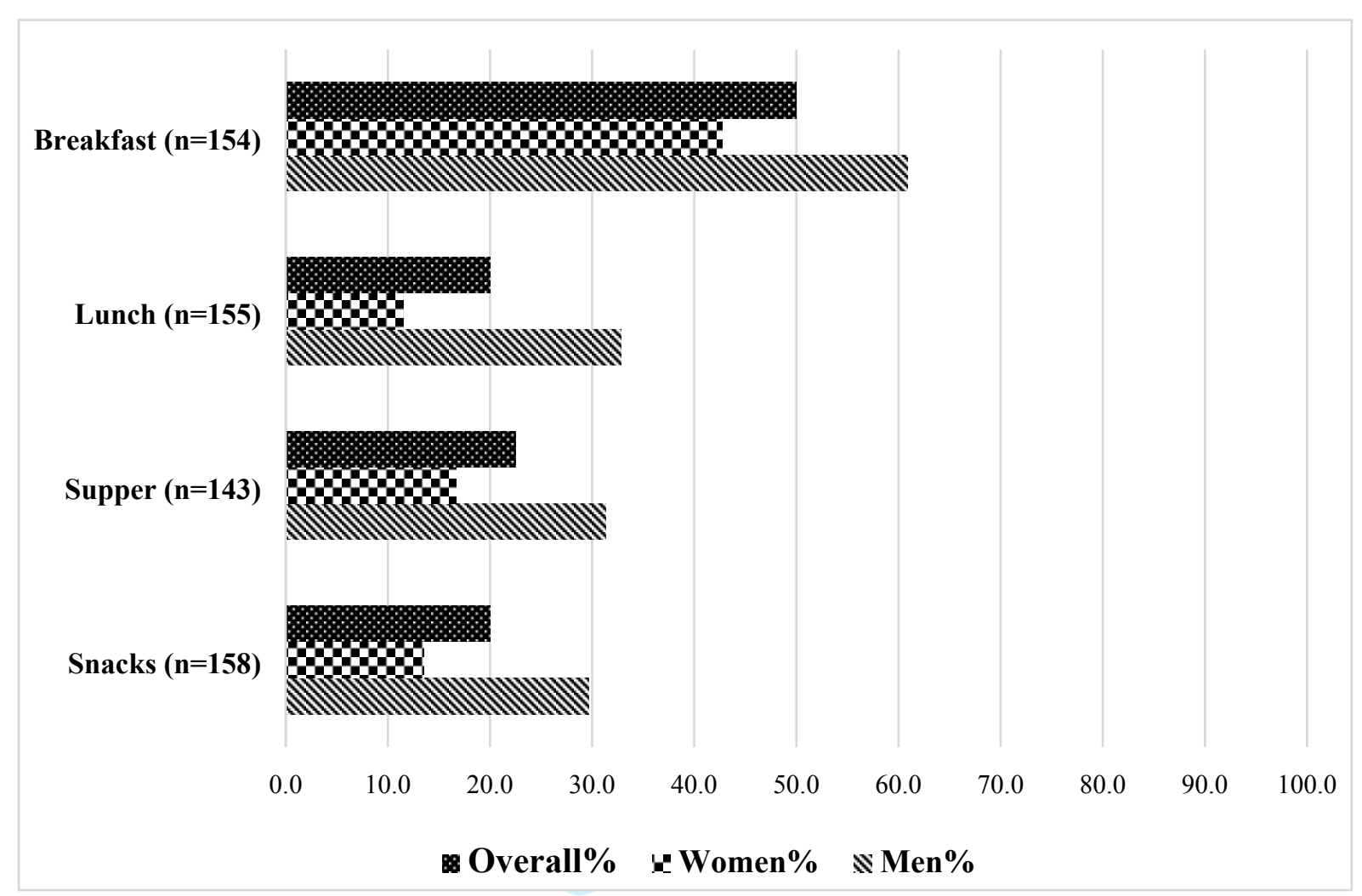

Figure 1: Proportion of Participants that included street food at different meals 